\title{
A social study on effects of personal characteristics on suicide attempt
}

\author{
Mohammad Reza Iravani ${ }^{a^{*}}$, Faezeh Taghipour ${ }^{\mathrm{b}}$, karam Allah Javanmard ${ }^{\mathrm{c}}$, Shahram Basity ${ }^{\mathrm{d}}$, Amin \\ Movahedi $^{\mathbf{e}}$
}

\footnotetext{
${ }^{a}$ Assistant Professor, Department of Social Work, Islamic Azad University Khomeinishahr Branch, Daneshjou Blvd, Iran.

${ }^{b}$ Assistant Professor, Department of Cultural Management Khorasgan (Isfahan) Branch, Islamic Azad University, Isfahan, Iran

${ }^{c}$ Assistant professor in Social work, University of Grand Ayatollah Brojerdi, Brojerd, Iran

${ }^{d}$ PHD, Department of Social Sciense, Payame Noor University/PO BOX 19395-3697 Tehran, (Iran)
}

${ }^{e}$ Master of Social Work

\section{H R O N I C L E}

Article history:

Received October 20, 2012

Received in revised format

16 December 2012

Accepted 19 December 2012

Available online

December 202012

Keywords:

Suicide attempt

Education

Marital status

Age

Esfahan

\begin{abstract}
A B S T R A C T
Suicide attempt has been one of serious social problems in todays' modern society and many studies have been focused to detect different factors influencing this unfortunate issue. In this paper, we perform an empirical study among 897 people who had some experiences associated with suicide attempt. We have designed and distributed a questionnaire among them investigating the impact of four major issues including marital status, educational background, age and living status. The results of our survey indicate that married people tend to commit suicide more than single people do. The other observation indicates that more educated people are more likely to commit suicide, older people are more interested in ending their lives and finally, people who live in cities are more likely to commit suicide than other people.
\end{abstract}

(C) 2013 Growing Science Ltd. All rights reserved.

\section{Introduction}

Suicide is one of the ten leading reasons of death in the world, accounting for over a million deaths annually and there are many studies to detect important factors influencing suicide attempts. According to Sher et al. (2001) suicide is related to mood disorders, where risk factors for suicide in mood disorders is normally organized according to whether their impact is on the threshold or diathesis for suicidal actions or whether they serve mainly as triggers. Predisposition to suicidal behavior or diathesis is a key factor, which faciliates to differentiate patients who are at high risk versus others. The purpose of severity of mood disorders does not detect depressed patients at high risk for suicide attempt. There are some agreements over the suicide risk related characteristics of depression such as psychotic features, agitation, etc. as part of bipolar disorder. Risk factors

*Corresponding author. Tel: +989130758065

E-mail addresses: iravani@iaukhsh.ac.ir (M.R. Iravani)

(c) 2013 Growing Science Ltd. All rights reserved. doi: 10.5267/j.msl.2012.12.019 
influencing the diathesis for suicidal behavior incorporate family history of suicide, low cerebrospinal fluid 5-hydroxyindolacetic acid, etc. Detecting high risk patients and effective treatment are needed for suicide prevention to alleviate morbidity and mortality in affective disorders.

Fergusson and Lynskey (1995) did a survey to explain the prevalence of suicide attempts and suicidal ideation in a birth cohort of New Zealand children studied to the age of 16 years. They also tried to investigate the extent in which risks of suicide attempts and suicidal ideation varied with various levels of adolescent psychopathology and concluded that $12 \%$ of this cohort reported suicidal ideation before the age of 16 years and 3\% attempted suicide.

Kung et al. (2005) performed an investigation to find out whether the substance use issues of excessive alcohol use and marijuana, firearm availability, depressive symptoms, and mental health service utilization, differed among white and African American suicide decedents compared with natural cause-of-death decedents. The study contributed to the limited understanding of how risk factors unique to suicide differ, and possibly interact, among African American and white decedents.

Riala et al. (2009) studied the relationship between regular daily smoking in adolescence and in adulthood, the onset age of suicidal behavior, and the repetitiveness of suicide attempts by the age of 31 years nd reported that there were some correlation between smoking and suicide attempts. Rezaie et al. (2011) compared warning signs prior to suicide attempt by self-immolation versus suicide attempt by self-poisoning among consecutive referrals for treatment after suicide-attempt at Kermanshah Imam Khomeini Hospital, Iran. They concluded that warning signs for suicide by selfimmolation were different. They concluded that prediction and prevention of suicide by selfimmolation could be more difficult than prevention of suicide by other methods.

Wan and Leung (2010) investigated different factors accounting for youth suicide attempt in Hong Kong. They investigated family relationship, presence of psychopathology, life stressors, and suicide ideation were potulated as mediators, leading to youth suicide attempt. According to Bhatia et al. (2006) suicide has been one of the most important causes of death among people who suffer from schizophrenia and there have been various reason to blame. They investigated different variables in two independent cross-national samples ascertained using identical protocols and concluded that the effect of known risk factors for suicide attempts among patients with schizophrenia differed across ethnic groups.

Mohanty et al. (2007) identified different risk groups by investigating in the four-year period over the period 2000-2003 and they 588 autopsied suicide victims. Information was obtained by interviewing the acquaintances of the victim, perusal of hospital records and the autopsy findings. They analyzed all the cases such as sex, age, and methods of suicide, seasonal variation, diurnal variation and other sociological aspects.

The study depicted a suicidal rate of 11.76 per 100,000 population where males and females were almost equally the sufferers. In their survey, the largest number of victims were in the age group of 21-30 years while majority of the victims were mentally sound, married and they were from rural background. Victims were mostly drawn from low socioeconomic status (48\%) and less educated or illiterates were usually the victims.

Chu et al. (2010) performed a comprehensive analysis of literature investigating the relationship between cultural factors and suicide in three major ethnic groups including African Americans, Asian Americans, and Latinos and LGBTQ sexual minority groups. They utilized an inductive method to synthesize this variegated body of research into four factors, which accounted for $95 \%$ of existing culturally specific risk data including cultural sanctions, idioms of distress, minority stress, and social discord. 
In this paper, we study the effects of four different personal factors on suicide attact among people who lived in Province of Esfahan, Iran during the year of 2011. The organization of this paper first present details of our survey in section 2 while section 3 explains the results. Concluding remarks are given in the last to summarize the contribution of this paper.

\section{The proposed study}

The proposed study of this paper selects a sample size from the people who made suicide attempt during the year of 2011 and all sample sizes were selected, randomly. In our survey, 897 people representing $97.4 \%$ of the participants were married and the remaining 24 people or $2.6 \%$ of the surved people were single. In our survey, surved people had different levels of educational backgrounds shown in Fig. 1 as follows,

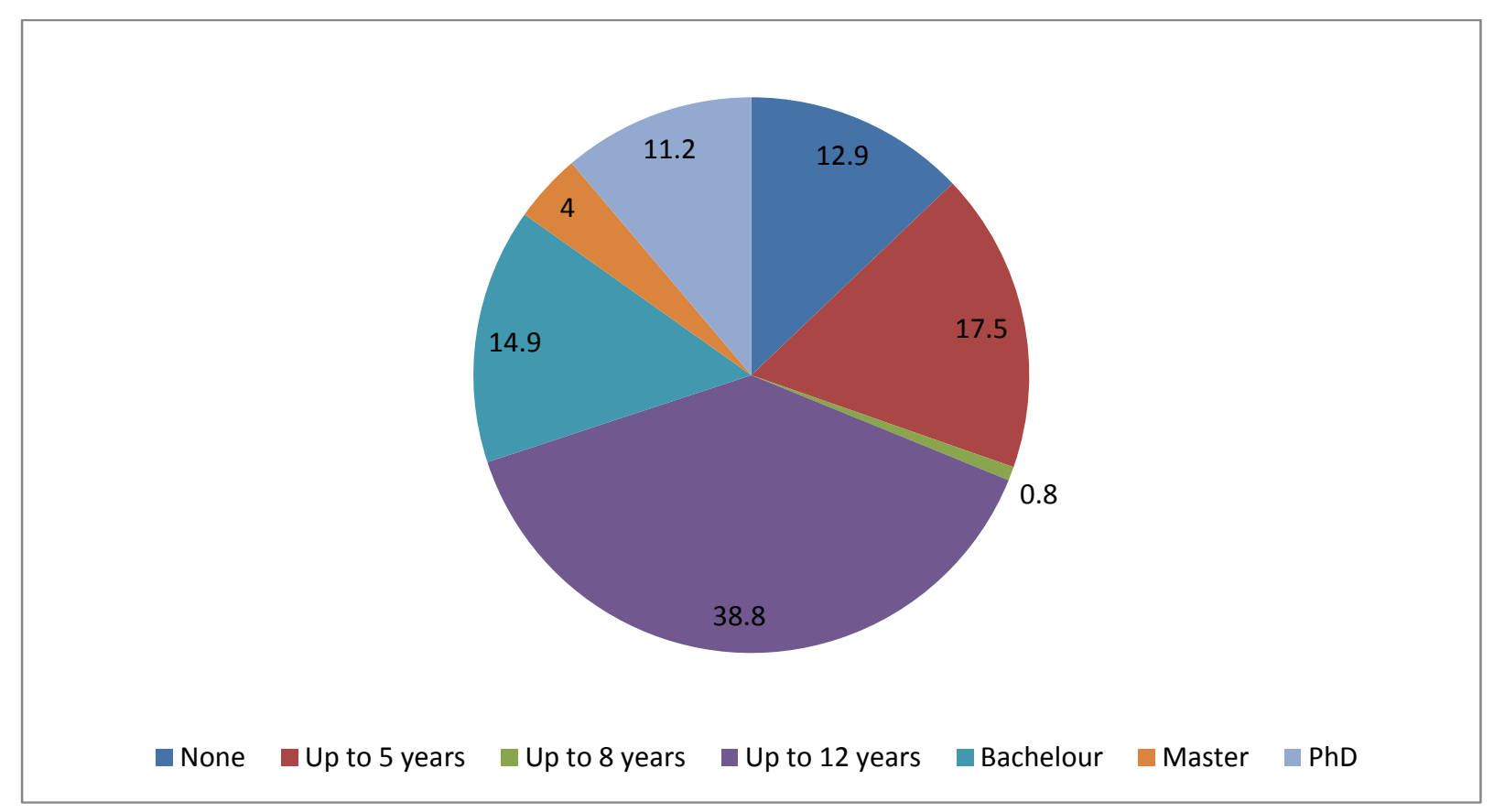

Fig. 1. Educational backgrounds of the participants

As we can observe from the results of Fig. 1, 12.9\% of the participants had no educational background, $17.5 \%$ of them had only up to five years of educational background and $70 \%$ of the participants had no university educations and the remaining $30 \%$ of the survyed people had different university educations. In terms of participants aging perspectives, $43.8 \%$ of the participants were 21 to 35 years old, $46.4 \%$ of them were 36 to 50 years old and only $9.9 \%$ of them were older.

In our survey, $67.6 \%$ of the participants were living in cities and $32.4 \%$ of the were residing in small towns. We have asked our participants whether they had any intension to commit suicide or not and 103 people representing $11.2 \%$ stated no, 776 people or $84.3 \%$ of the participants stated that they had some intentions for commiting suitcide and 42 people or $4.2 \%$ did not answer our question. The proposed study of this paper considers the following hypotheses.

1. There is a relationship between marital status and attempt to commit suitcide.

2. There is a relationship between educational background and intention to commit suicite.

3. There is a relationship between age and suicide attempt.

4. There is a relationship between residency status, city or town, and suicide attempt. 
We examine these four hypotheses based on Chi-Square test. Next, we present details of our findings of the survey.

\section{The results}

In this section, we present the results of our survey using non-parametric analysis.

\subsection{Martial status and suicide}

The results of the implementation of Chi-Square yields 293.08 with Sig=0.000. Therefore, we can conclude that there is a meaningful relationship between marital status and suicide attempt. Table 1 demonstrates details of the survey in terms of marital status and suicide attempt.

\section{Table 1}

The summary of surveyed people in terms of marital status

\begin{tabular}{llcc}
\hline Suicide attempt & & \multicolumn{2}{c}{ Marital status } \\
\cline { 3 - 4 } & & Married & Single \\
\hline \multirow{2}{*}{ No } & Frequency & 97 & 6 \\
& Percentage & $10.8 \%$ & $25 \%$ \\
\hline \multirow{2}{*}{ Yes } & Frequency & 776 & 0 \\
& Percentage & $86.5 \%$ & $0 \%$ \\
\hline \multirow{2}{*}{ Not applicable } & Frequency & 24 & 18 \\
& Percentage & $2.7 \%$ & $75 \%$ \\
\hline \multirow{2}{*}{ Total } & Frequency & 897 & 24 \\
& Percentage & 100 & 100 \\
\hline
\end{tabular}

\subsection{Educational background and suicide attempt}

The results of the implementation of Chi-Square yields 82.396 with Sig=0.000. Therefore, we can conclude that there is a meaningful relationship between educational background and suicide attempt. In other words, as we can increase in people's educational background, there is an increase in suicide attempt. Table 2 demonstrates details of the survey in terms of educational background and suicide attempt.

Table 2

The summary of surveyed people in terms of educational background

\begin{tabular}{llcccc}
\hline \multirow{2}{*}{ Suicide attempt } & & \multicolumn{4}{c}{ Educational background } \\
\cline { 3 - 6 } & & None & Less than 5y & Less than 14 & Master/Phd \\
\hline \multirow{2}{*}{ No } & Frequency & 15 & 6 & 57 & 25 \\
& Percentage & $12.6 \%$ & $3.6 \%$ & $11.5 \%$ & $17.9 \%$ \\
\hline \multirow{2}{*}{ Yes } & Frequency & 92 & 138 & 437 & 109 \\
& Percentage & $77.3 \%$ & $82.1 \%$ & $88.5 \%$ & $77.9 \%$ \\
\hline \multirow{2}{*}{ Not applicable } & Frequency & 12 & 24 & 0 & 6 \\
& Percentage & $10.1 \%$ & $14.3 \%$ & $0 \%$ & $4.3 \%$ \\
\hline \multirow{2}{*}{ Total } & Frequency & 119 & 168 & 494 & 140 \\
& Percentage & $100 \%$ & $100 \%$ & $100 \%$ & $100 \%$ \\
\hline
\end{tabular}

\subsection{Age and suicide attempt}

The results of the implementation of Chi-Square yields 31.825 with Sig $=0.000$. Therefore, we can conclude that there is a meaningful relationship between age and suicide attempt. In other words, as 
we can increase in people's age, there is an increase in suicide attempt. Table 3 demonstrates details of the survey in terms of age and suicide attempt.

Table 3

The summary of surveyed people in terms of age

\begin{tabular}{llccc}
\hline & & & Age & \\
\hline Suicide attempt & & $21-35$ & $36-50$ & $51-65$ \\
\hline \multirow{2}{*}{ No } & Frequency & 57 & 46 & 0 \\
& Percentage & $14.1 \%$ & $10.8 \%$ & $0 \%$ \\
\hline \multirow{2}{*}{ Yes } & Frequency & 328 & 369 & 79 \\
& Percentage & $81.4 \%$ & $86.4 \%$ & $86.8 \%$ \\
\hline \multirow{2}{*}{ Not applicable } & Frequency & 18 & 12 & 12 \\
& Percentage & $4.5 \%$ & $2.8 \%$ & $13.2 \%$ \\
\hline \multirow{2}{*}{ Total } & Frequency & 403 & 427 & 91 \\
& Percentage & $100 \%$ & $100 \%$ & $100 \%$ \\
\hline
\end{tabular}

\subsection{Living status and suicide attempt}

The results of the implementation of Chi-Square yields 63.07 with Sig=0.000. Therefore, we can conclude that there is a meaningful relationship between age and suicide attempt. According to our survey people who live cities tend to commite suicide more than people who live in small towns. Table 4 demonstrates details of the survey in terms of living status and suicide attempt.

\section{Table 4}

The summary of surveyed people in terms of living status

\begin{tabular}{llcc}
\hline Suicide attempt & & \multicolumn{2}{c}{ Residency status } \\
\cline { 3 - 4 } & & Town & City \\
\hline No & Frequency & 6 & 97 \\
& Percentage & $2.0 \%$ & $15.6 \%$ \\
\hline \multirow{2}{*}{ Yes } & Frequency & 292 & 484 \\
& Percentage & $98.0 \%$ & $77.7 \%$ \\
\hline \multirow{2}{*}{ Not applicable } & Frequency & 0 & 42 \\
& Percentage & $0 \%$ & $6.7 \%$ \\
\hline \multirow{2}{*}{ Total } & Frequency & 298 & 623 \\
& Percentage & 100 & 100 \\
\hline
\end{tabular}

As we have observed, the increase in age and education has increased suicide attempt and this is in contradiction to what Mohanty et al. (2007). The moral stody is that personal charactersitics may have different impacts in various societies. In other words, it is not an easy task to make conclusion for all societies solely based on people's personal characteristics. People in different parts of the world may decide to end their lives for various reasons, which may or may not depend on their age and educational level.

\section{Conclusion}

In this paper, we have presented an empirical survey to find out the relationship between three personal characteristics and one demographic factor on suitcide attempt. The study was performed on 897 people during the year of 2011 who had some experiences of suicide attempt. The results of our study have shown that when there was an increase in people' age, educational background there was a 
higher chance of suicide attempt. In addition, the result of our survey has concluded that married people were more likely to attempt suicide than single people did. Finally, we have observed that people who live in cities were more likely to attmpt to end their lives than people who lived in small towns. There many be several reasons behind this since people who live in big cities may face more challengous such as facing with higher living expenses, higher life expectations, etc.

\section{Acknowledgment}

The authors would like to thank the annonymous referees for constructive comments on earlier version of this paper.

\section{Reference}

Bhatia, T., Thomas, P., Semwal, P., Thelma, B.K., Nimgaonkar, V.L., \& Deshpande, S.N. (2006). Differing correlates for suicide attempts among patients with schizophrenia or schizoaffective disorder in India and USA. Schizophrenia Research, 86(1-3), 208-214.

Chu, J.P., Goldblum, P., Floyd, R., \& Bongar, B. (2010). The cultural theory and model of suicide. Applied and Preventive Psychology, 14(1-4), 25-40

Fergusson, D.M., \& Lynskey, M.T, (1995). Suicide Attempts and Suicidal Ideation in a Birth Cohort of 16-Year-Old New Zealanders. Journal of the American Academy of Child \& Adolescent Psychiatry, 34(10), 1308-1317.

Kung, H.C., Pearson, J.L., \& Wei, R. (2005). Substance Use, Firearm Availability, Depressive Symptoms, and Mental Health Service Utilization Among White and African American Suicide Decedents Aged 15 to 64 Years. Annals of Epidemiology, 15(8), 614-621

Mohanty, S., Sahu, G., Mohanty, M.K., \& Patnaik, M. (2007). Suicide in India - A four year retrospective study. Journal of Forensic and Legal Medicine, 14(4), 185-189

Rezaie, L., Khazaie, H., Soleimani, A., Schwebel, D.C. (2011). Self-immolation a predictable method of suicide: A comparison study of warning signs for suicide by self-immolation and by selfpoisoning. Burns, 37(8), 1419-1426.

Riala, K., Taanila, A., Hakko, H., \& Räsänen, P. (2009). Longitudinal Smoking Habits As Risk Factors for Early-Onset and Repetitive Suicide Attempts: The Northern Finland 1966 Birth Cohort Study. Annals of Epidemiology,19(5), 329-335.

Sher, L., Oquendo, M.A., \& Mann, J.J. (2001). Risk of suicide in mood disorders. Clinical Neuroscience Research, 1(5), 337-344

Wan, G.W.Y., \& Leung, P.W.L. (2010). Factors accounting for youth suicide attempt in Hong Kong: A model building. Journal of Adolescence, 33(5), 575-582. 